\title{
Ambient air pollution triggers wheezing symptoms in infants
}

\author{
Z J Andersen, ${ }^{1,2}$ S Loft, ${ }^{2}$ M Ketzel, ${ }^{3}$ M Stage, ${ }^{4}$ T Scheike, ${ }^{1}$ M N Hermansen, ${ }^{4}$ \\ H Bisgaard ${ }^{4}$
}

${ }^{1}$ Department of Biostatistics, University of Copenhagen, Copenhagen, Denmark;

${ }^{2}$ Department of Environmental and Occupational Health,

Copenhagen University, Copenhagen, Denmark:

${ }^{3}$ Department of Atmospheric Environment, National Environmental Research Institute, Aarhus University, Denmark; ${ }^{4}$ Danish Paediatric Asthma Centre, Copenhagen University Hospital, Gentofte Copenhagen

Correspondence to: Mrs Z J Andersen, Department of Biostatistics, Institute of Public Health, Copenhagen University, Øster Farimagsgade 5 Entr. B, P 0 Box 2099, 1014 Copenhagen K, Denmark; zorana@cancer.dk

Received 12 June 2007 Accepted 16 January 2008 Published Online First 11 February 2008

\begin{abstract}
Background: There is limited evidence for the role of air pollution in the development and triggering of wheezing symptoms in young children. A study was undertaken to examine the effect of exposure to air pollution on wheezing symptoms in children under the age of 3 years with genetic susceptibility to asthma.

Methods: Daily recordings of symptoms were obtained for 205 children participating in the birth cohort study Copenhagen Prospective Study on Asthma in Children and living in Copenhagen for the first 3 years of life. Daily air pollution levels for particulate matter $<10 \mu \mathrm{m}$ in diameter $\left(\mathrm{PM}_{10}\right)$ and the concentrations of ultrafine particles, nitrogen dioxide $\left(\mathrm{NO}_{2}\right)$, nitrogen oxide $\left(\mathrm{NO}_{\mathrm{x}}\right)$ and carbon monoxide (CO) were available from a central background monitoring station in Copenhagen. The association between incident wheezing symptoms and air pollution on the concurrent and previous 4 days was estimated by a logistic regression model (generalised estimating equation) controlling for temperature, season, gender, age, exposure to smoking and paternal history of asthma.
\end{abstract}

Results: Significant positive associations were found between concentrations of $\mathrm{PM}_{10}, \mathrm{NO}_{2}, \mathrm{NO}_{x}, \mathrm{CO}$ and wheezing symptoms in infants (aged $0-1$ year) with a delay of 3-4 days. Only the traffic-related gases $\left(\mathrm{NO}_{2}\right.$, $N O_{x}$ ) showed significant effects throughout the 3 years of life, albeit attenuating after the age of 1 year.

Conclusions: Air pollution related to traffic is significantly associated with triggering of wheezing symptoms in the first 3 years of life.

Recurrent wheeze represents a serious health burden in young children and is the cause of a considerable number of hospital admissions and other health care expenditure. ${ }^{1}$ Evidence for the role of air pollution in causing such symptoms remains equivocal. ${ }^{23}$ Particulate air pollution in terms of particulate matter $<10$ and $2.5 \mu \mathrm{m}$ in diameter $\left(\mathrm{PM}_{10}\right.$ and $\left.\mathrm{PM}_{2.5}\right)$ has been linked to asthma exacerbations in school children, ${ }^{4-12}$ suggesting a role as a trigger of symptoms, although two large multicentre studies failed to confirm this. ${ }^{13}{ }^{14}$ Recently, ultrafine particles (UFPs; particles $<0.1 \mu \mathrm{m}$ in diameter) generated by traffic emissions were suggested to have particularly strong effects in the airways due to a high level of pulmonary deposition and their ability to induce inflammation and oxidative stress. ${ }^{15}$ However, the only epidemiological study of the effects of UFPs in children to date found only a weak association with asthma symptoms in school children. ${ }^{8}$ Traffic-related air pollution, assessed by nitrogen dioxide $\left(\mathrm{NO}_{2}\right)$ exposure or proximity to traffic, has been more consistently associated with asthma exacerbations in school children, which suggests that air pollution is an important trigger of symptoms. ${ }^{16-20}$

Only a few studies of the effects of air pollution are available in young children and provide mixed evidence. $^{21-27}$ A greater susceptibility of younger children compared with school children may be suspected because of the development of the lung and the higher ventilation rates in early life. ${ }^{2} \mathrm{~A}$ case-control study has found significant associations between traffic pollution and asthma before the age of 3 years which attenuated between the ages of 3 and 14 years. ${ }^{20}$ Understanding the effects of early exposure to air pollution on the development and triggering of wheeze may give important clues to its role in the development of asthma later in life. ${ }^{3}$ To date, most studies in young children have used geographical variations in air pollutant levels and have focused on traffic. ${ }^{20}{ }^{21} 23-26$ Only one studied $\mathrm{PM}_{10}{ }^{22}$ and one studied ozone $\left(\mathrm{O}_{3}\right){ }^{27}$ with no evidence to date on the effect of UFPs. One study in preschool children found an association between soot and incident wheeze, asthma and ear/nose/throat infections in a birth cohort of children up to 4 years of age, ${ }^{21}$ and a second study in preschool children found an association between $\mathrm{PM}_{10}$ and the prevalence and incidence of respiratory symptoms in a survey of children aged 1-5 years. ${ }^{22}$ While proximity to traffic was recently reported to be associated with wheeze in infants, ${ }^{23}$ only two birth cohort studies have examined susceptibility in small children by age, reporting associations between doctor-diagnosed asthma ${ }^{24}$ and respiratory symptoms (cough) ${ }^{25}$ and traffic to be stronger in the first year of life than in the second year of life. Finally, the potential importance of genetic susceptibility has been suggested by a particularly strong association between triggering of wheezing bronchitis or wheeze and $\mathrm{PM}_{2.5}$ and $\mathrm{O}_{3}$, respectively, among infants with a family history of asthma. ${ }^{26}$

In this study we used the unique data on daily symptom recording in the birth cohort of children of mothers with asthma from the Copenhagen Prospective Study on Asthma in Childhood (COPSAC) to determine the short-term impact of particulate $\left(\mathrm{PM}_{10}\right.$ and UFPs) and gaseous (nitrogen oxide $\left(\mathrm{NO}_{\mathrm{x}}\right), \mathrm{NO}_{2}$ and carbon monoxide (CO)) air pollution on the triggering of wheezing symptoms during the first 3 years of life in this high-risk population. We examined the susceptibility by age (infants ( $0-1$ year), $1-2$ years and $2-3$ years) to study the hypothesis of increased susceptibility of infants to air pollution, and tested for effect 
modification by medication use, gender and paternal asthma history.

\section{METHODS}

\section{Study population}

The COPSAC prospective longitudinal birth cohort study includes 411 Danish children born to mothers with asthma and was designed to study the gene-environment interaction in the development of asthma and other atopic diseases. ${ }^{28-30}$ In brief, pregnant women identified through the Danish National Birth Cohort Study and prenatal clinics, living in Copenhagen, fluent in Danish, with a history of physician-diagnosed asthma after the age of 7 years and a history of daily treatment with inhaled $\beta_{2}$ agonists or glucocorticoids (minimum of 2 weeks during two seasons or continuously for 1 year) were invited to participate in the study. Infants with a severe congenital abnormally, a gestational age $<36$ weeks, a need for mechanical ventilation or a lower respiratory tract infection were excluded. The eligible 411 children of 394 mothers (nine pair of twins and eight siblings) were born between 2 August 1998 and 12 December 2001 and enrolled in the cohort at the Clinical Research Unit (CRU) visit at 1 month of age, with follow-up clinical investigations every 6 months until the age of 7 years and at any episode of symptoms.

At the first CRU visit parents were given diary cards (http:// ipaper.dk/copsac/Asthma_in_young) and instructed to record their child's wheezing symptoms daily as dichotomised scores (yes/no), as previously described. ${ }^{29}$ The CRU doctor reviewed the symptom definitions and the diary entries with parents at the 6-monthly clinical sessions and at acute episodes of wheeze. Diary recordings for the first 3 years of life were used in the current analyses. Information on exposure to smoking at home and paternal history of asthma was obtained by interviews. Medication use followed the algorithm described in detail elsewhere..$^{29}$

Information on addresses, including relocations, was available from the COPSAC database and the Danish National Person Registry, allowing for geocoding and calculation of the exact distance from the residence to the air pollution monitor in the centre of Copenhagen on a daily basis. Thus, 205 children living within a $15 \mathrm{~km}$ radius of the central monitor during the first 3 years of life were selected for the study.

\section{Assessment of air pollution exposure}

The pollutant and meteorological data were measured by the Danish National Environmental Research Institute at a fixed urban background monitor (20 $\mathrm{m}$ height) in the centre of Copenhagen with minimal contribution from local sources, in accordance with WHO guidelines. Main streets are located about $300 \mathrm{~m}$ west and $50 \mathrm{~m}$ east of the monitor, with 26000 and 56000 vehicles passing per working day, respectively. For the study period (12 December 1998 to 19 December 2004), daily (24 h, midnight-to-midnight) mean concentrations were available for $\mathrm{PM}_{10}$ (SM200 monitor; Opsis, Sweden), CO (M300; API, San Diego, USA), $\mathrm{NO}_{2}$ and $\mathrm{NO}_{\mathrm{x}}$ (M200A; API), $\mathrm{O}_{3}$ (M400; API) and temperature, with missing data on days with equipment malfunctions. Although the total number of concentration measurements included particles $10-700 \mathrm{~nm}$ in diameter, we define them as $\mathrm{UFP}_{\mathrm{NC}}$ in this study because particles $<100 \mathrm{~nm}$ (by definition, UFP) comprised more than $95 \%$ of the total concentration measurements. Monitoring of UFP $_{\text {NC }}$ (Differential Mobility Particle Sizer, Roskilde, Denmark) ${ }^{31}$ and $\mathrm{PM}_{2.5}$ (TEOM Ambient Particulate Monitor;
Rupprecht and Patashnick, USA) began in Denmark on 15 May 2001 and 3 October 2003, respectively.

\section{Statistical analysis}

The incidence of wheezing symptoms was defined as the first day of a registered symptom. Logistic regression analyses were performed using generalised estimating equations $(\mathrm{GEE})^{32}$ by the GENMOD procedure with exchangeable correlation structure using SAS Version 9.1. Pollutant concentrations were logtransformed. Analyses were conducted for all 3 years and separately for infants and age groups $1-2$ and 2-3 years. We first fitted single-pollutant models, adjusted for age (dummy for each year), gender, exposure to passive smoking, paternal history of asthma, $24 \mathrm{~h}$ mean temperature (linearly) and calendar season (dummy). Pollutant concentrations on the same day (lag 0 ), previous day (lag 1 ), up to 4 days before a new symptom (lag 4) and the 3-day mean (2-4 days) were considered. In cases where monitor data were missing from single days, 3-day means of available measurements were used. Two-pollutant models were fitted for 3-day mean pollutant concentrations to examine the robustness of one-pollutant associations. Separate analyses were conducted for a subset of data where $\mathrm{UFP}_{\mathrm{NC}}$ data were available (15 May 2001 to 19 December 2004) to ensure comparability between the effect of $\mathrm{UFP}_{\mathrm{NC}}$ and other pollutants. Finally, we tested for effect modification by gender, medication use and paternal history of asthma. Effects were reported as odds ratios (ORs) per interquartile range (IOR) increase in exposure.

A number of sensitivity analyses were performed. The results remained unchanged when fitting a GEE model with alternative correlation structures (independent, autoregressive). Various adjustments for meteorology and seasonal/time trend effects were tested. A model with temperature defined by a dummy per 25 th percentile showed similar results and indicated a strong negative trend on symptom development by increasing quartiles of temperature, validating linear modelling of temperature. Season was modelled by dummy variables for calendar seasons, with a significant trend seen for an increase of symptoms in colder seasons. After adjusting for season and temperature, additional time trends including calendar time (linearly and by smoothing spline) and dummy for each month were not significant and not included in the model. Finally, we performed analyses for an alternative choice of study population with 110 COPSAC children living within a $5 \mathrm{~km}$ radius from the central monitor.

\section{RESULTS}

The 205 children ( 99 boys) in the COPSAC cohort lived within a $15 \mathrm{~km}$ radius of the central monitor, with a mean (SD) distance of $6.1(4.0) \mathrm{km}$ and a minimum distance of $0.3 \mathrm{~km}$. Of the 205 children, 35 had a paternal history of asthma and 94, 64 and 47 were exposed to passive smoking for $<10,10-100$ and $>100$ days/year, respectively. The 205 children seemed representative of the whole COPSAC cohort, ${ }^{29}$ with a dropout rate of $3(1.5 \%), 6(3 \%)$ and $2(1 \%)$ children in the first, second and third year of life, respectively, and 194 (95\%) active children at their third birthday. The average observation period per child was 850 days (minimum 23, maximum 1097), with a total of 174259 person-days and $15.4 \%$ diary entries missing. Thirtythree children $(16 \%)$ experienced no wheezing symptoms in the first 3 years of life. A prevalence of 6.2 per 100 person-days (total of 10779 symptom-days) and an incidence of 1 per 100 person-days (1591 new symptom-days) was observed. 
Table 1 Air pollutant levels and meteorological conditions in Copenhagen from 12 December 1998 to 19 December 2004 (2199 days)

\begin{tabular}{lrllll}
\hline & $\mathbf{N}$ & Mean $(\mathbf{S D})$ & 25th percentile & 75th percentile & IOR $^{*}$ \\
\hline Pollutants & & & & & \\
$\mathrm{PM}_{10}\left(\mu \mathrm{g} / \mathrm{m}^{3}\right)$ & 1749 & $25.1(16.7)$ & 15.7 & 30.2 & 14.5 \\
$\mathrm{PM}_{2.5} \dagger\left(\mu \mathrm{g} / \mathrm{m}^{3}\right)$ & 453 & $9.8(4.5)$ & 6.8 & 11.7 & 4.9 \\
$\mathrm{UFP}_{\mathrm{NC}}:\left(\mathrm{particles} / \mathrm{cm}^{3}\right)$ & 602 & $8092(3470)$ & 5706 & 9825 & 4119 \\
$\mathrm{NO}_{2}(\mathrm{ppb})$ & 2045 & $11.8(5.1)$ & 8.1 & 14.6 & 6.5 \\
$\mathrm{NO} \mathrm{N}_{\mathrm{x}}(\mathrm{ppb})$ & 2045 & $15.2(8.7)$ & 9.5 & 18.4 & 8.9 \\
$\mathrm{CO}(\mathrm{ppm})$ & 2068 & $0.29(0.10)$ & 0.22 & 0.34 & 0.12 \\
$\mathrm{O}_{3}(\mathrm{ppb})$ & 680 & $25.0(9.9)$ & 18.2 & 31.8 & 13.6 \\
Meteorology (units) & & & & \\
Temperature $\left({ }^{\circ} \mathrm{C}\right)$ & 2143 & $9.3(6.6)$ & 3.9 & 14.7 & 10.8 \\
Relative humidity $(\%)$ & 2142 & $75.2(11.4)$ & 67.3 & 83.7 & 16.4 \\
Wind speed $(\mathrm{m} / \mathrm{s})$ & 2092 & $4.2(1.5)$ & 3.1 & 5.0 & 1.9 \\
Global radiation $\left(\mathrm{W} / \mathrm{m}^{2}\right)$ & 2128 & $114.1(95.5)$ & 25.5 & 189.3 & 163.8 \\
\hline
\end{tabular}

CO, carbon monoxide; IQR, interquartile range; $\mathrm{NO}_{\mathrm{x}}$, nitrogen oxide; $\mathrm{NO}_{2}$, nitrogen dioxide; $\mathrm{O}_{3}$, ozone; $\mathrm{PM}_{2.5}, \mathrm{PM}_{10}$, particulate matter $<2.5$ and $<10 \mu \mathrm{m}$ in diameter; $\mathrm{UFP}_{\mathrm{NC}}$, ultrafine particles.

${ }^{*} \mathrm{IQR}=75$ th -25 th percentile.

$\dagger$ Measurements of $\mathrm{PM}_{2.5}$ were carried out by a TEOM instrument operated at $50^{\circ} \mathrm{C}$ in order to dry the aerosol, resulting in loss of volatile compounds (ammonium nitrate and semivolatile organic compounds). Thus, in general TEOM measurements give smaller $\mathrm{PM}_{2.5}$ values than the gravimetric or beta-attenuation method, with a difference of $8-10 \mu \mathrm{g} / \mathrm{m}^{3}$.

Total concentration of ultrafine particles $10-700 \mathrm{~nm}$ in diameter ( $95 \%$ of total concentration comes from particles $<100 \mathrm{~nm}$ ).

Tables 1 and 2 show the pollution and meteorological conditions in Copenhagen during the study period. Frequent breakdown or other utilisation of the $\mathrm{UFP}_{\mathrm{NC}}$ measuring equipment caused missing data gaps (54\%). $\mathrm{PM}_{2.5}$ and $\mathrm{O}_{3}$ data were not sufficient for analyses of all three age groups due to the late start of $\mathrm{PM}_{2.5}$ monitoring (3 October 2003) and a monitoring gap for $\mathrm{O}_{3}$ in the middle of the study period (13 July 1999 to 1 July 2003). Strong correlations were observed between $\mathrm{PM}_{10}$ and $\mathrm{PM}_{2.5}, \mathrm{CO}$ and $\mathrm{NO}_{2} / \mathrm{NO}_{\mathrm{x}}$, and $\mathrm{UFP}_{\mathrm{NC}}$ and $\mathrm{NO}_{2} / \mathrm{NO}_{\mathrm{x}}$ (table 2) and weak correlations were observed between $\mathrm{PM}_{10}$ and $\mathrm{UFP}_{\mathrm{NC}}$ and $\mathrm{PM}_{10}$ and $\mathrm{NO}_{2} / \mathrm{NO}_{\mathrm{x}}$.

Air pollution showed delayed adverse effects, which were strongest and most significant in infants with a 4-day delay for $\mathrm{PM}_{10}$ and a 3-day delay for $\mathrm{NO}_{2}, \mathrm{NO}_{\mathrm{x}}$ and $\mathrm{CO}$. In this group an increase of one IOR in exposure to $\mathrm{PM}_{10}, \mathrm{NO}_{2}, \mathrm{NO}_{\mathrm{x}}$ and $\mathrm{CO}$ resulted in an increase in wheezing symptoms of $23 \%(95 \%$ confidence interval (CI) $2 \%$ to $48 \%$; lag 4; IOR $\left.14 \mu \mathrm{g} / \mathrm{m}^{3}\right), 42 \%$ (95\% CI $15 \%$ to $77 \%$; lag 3; IOR $6.5 \mathrm{ppb),30 \%} \mathrm{(95 \%} \mathrm{CI} 9 \%$ to $53 \%$; lag 3; IOR 8.9 ppb) and $47 \%$ (95\% CI $10 \%$ to $96 \%$; lag 3 ; $0.12 \mathrm{ppm}$ ), respectively (table 3). Associations for $\mathrm{NO}_{2}$ and $\mathrm{NO}_{x}$ were also significant with a 4-day lag and 3-day means. Similar lag structures were observed for the pollutants in all 3 years, but the effects were attenuated after 1 year of age. The associations remained positive and significant in all 3 years only for $\mathrm{NO}_{2}$ and $\mathrm{NO}_{x}$, for which an increase of one IOR in 3-day mean exposure was associated with an increase in wheezing symptoms of $19 \%$
(95\% CI $1 \%$ to $30 \% ; 6.5 \mathrm{ppb}$ ) and $14 \%$ (95\% CI $0 \%$ to $30 \%$; $8.9 \mathrm{ppb})$, respectively. The effects of $\mathrm{NO}_{2}$ and $\mathrm{NO}_{x}$ were stronger than those of $\mathrm{PM}_{10}$ throughout the study period (table 3), as confirmed in two-pollutant models for infants (table 4).

$U_{\text {NCP }}$ showed a relatively strong adverse effect with delays of 2-4 days in infants, but without reaching statistical significance, and this changed after the age of 1 year to an apparently protective effect. Analyses for 3-day mean concentrations of other pollutants $\left(\mathrm{PM}_{10}, \mathrm{NO}_{2}, \mathrm{NO}_{\mathrm{x}}\right.$ and $\left.\mathrm{CO}\right)$ were repeated for the subset of data where $\mathrm{UFP}_{\mathrm{NC}}$ measurements were available (15 May 2001 to 19 December 2004) for infants to enable direct comparisons (table 5). Associations for all pollutants were enhanced, with estimates for $\mathrm{UFP}_{\mathrm{NC}}$ comparable to those of $\mathrm{PM}_{10}$ and gases in one-pollutant models and higher than the others in two-pollutant models. For COPSAC children living within a $5 \mathrm{~km}$ radius of the monitor, the effects of $\mathrm{UFP}_{\mathrm{NC}}$ were enhanced reaching statistical significance for 3 day means (table 6) and for lags 2-4 (data not shown).

No effect modification was detected between air pollution and gender, paternal asthma history or medication use.

\section{DISCUSSION}

We found strong adverse effects of air pollution with $\mathrm{PM}_{10}$, $\mathrm{NO}_{2}, \mathrm{NO}_{\mathrm{x}}$ and $\mathrm{CO}$ on the triggering of wheezing symptoms in infants which attenuated after the age of 1 year. Independent

Table 2 Spearman correlation coefficients between air pollutants and temperature in Copenhagen from 12 December 1998 to 19 December 2004 (2199 days)

\begin{tabular}{llllllll}
\hline & $\mathbf{P M}_{\mathbf{2 . 5}}$ & $\mathbf{U F P}_{\mathbf{N C}}{ }^{*}$ & $\mathbf{N O}_{\mathbf{2}}$ & $\mathbf{N O}_{\mathbf{x}}$ & $\mathbf{C 0}$ & $\mathbf{0}_{\mathbf{3}}$ & Temperature \\
\hline $\mathrm{PM}_{10}$ & 0.79 & 0.37 & 0.43 & 0.40 & 0.45 & -0.32 & 0.25 \\
$\mathrm{PM}_{2.5}$ & & 0.40 & 0.41 & 0.39 & 0.45 & -0.20 & -0.01 \\
$\mathrm{UFP}_{\mathrm{NC}}$ & & & 0.67 & 0.65 & 0.52 & -0.12 & -0.06 \\
$\mathrm{NO}_{2}$ & & & & 0.98 & 0.75 & -0.58 & -0.21 \\
$\mathrm{NO}_{\mathbf{x}}$ & & & & & 0.74 & -0.62 & -0.21 \\
$\mathrm{CO}$ & & & & & & -0.63 & -0.52 \\
$0_{3}$ & & & & & & & 0.43
\end{tabular}

$\mathrm{CO}$, carbon monoxide; $\mathrm{NO}_{x}$, nitrogen oxide; $\mathrm{NO}_{2}$, nitrogen dioxide; $\mathrm{O}_{3}$, ozone; $\mathrm{PM}_{2.5}, \mathrm{PM}_{10}$, particulate matter $<2.5$ and $<10 \mu \mathrm{m}$ in diameter; $\mathrm{UFP}_{\mathrm{NC}}$, ultrafine particles.

${ }^{*}$ Total concentration of ultrafine particles $10-700 \mathrm{~nm}$ in diameter (95\% of total concentration comes from particles $\left.<100 \mathrm{~nm}\right)$. 
Table 3 Associations between incident wheezing symptoms and single-day and 3-day mean concentrations (lag 2-4) of air pollutants with maximum data available for each pollutant (12 December 1998 to 19 December 2004)

\begin{tabular}{|c|c|c|c|c|}
\hline & Age 0-1 & Age 1-2 & Age 2-3 & Age 0-3 \\
\hline & $\mathrm{OR}^{*}(95 \% \mathrm{CI})$ & OR (95\% CI) & OR (95\% CI) & OR (95\% CI) \\
\hline \multicolumn{5}{|l|}{$\mathrm{PM}_{10}\left(\mu \mathrm{g} / \mathrm{m}^{3}\right)$} \\
\hline $\mathrm{n} \dagger$ & 189 & 171 & 155 & 195 \\
\hline Lag 0 & $1.05(0.88$ to 1.25$)$ & $1.00(0.86$ to 1.15$)$ & $0.87(0.72$ to 1.06$)$ & $0.97(0.87$ to 1.08$)$ \\
\hline Lag 1 & $1.00(0.82$ to 1.22$)$ & $1.02(0.87$ to 1.19$)$ & $0.95(0.78$ to 1.15$)$ & $0.99(0.89$ to 1.10$)$ \\
\hline Lag 2 & $1.01(0.83$ to 1.23$)$ & $1.05(0.93$ to 1.19$)$ & $0.99(0.82$ to 1.17$)$ & $1.01(0.92$ to 1.12$)$ \\
\hline Lag 3 & $1.20(0.98$ to 1.46$)$ & 0.96 (0.84 to 1.09$)$ & $1.03(0.84$ to 1.25$)$ & $1.03(0.93$ to 1.14$)$ \\
\hline $\operatorname{Lag} 4$ & $1.23(1.02$ to 1.48$) \ddagger$ & $1.04(0.90$ to 1.21$)$ & $0.89(0.74$ to 1.09$)$ & $1.04(0.94$ to 1.15$)$ \\
\hline 3-day mean§ & $1.21(0.99$ to 1.48$)$ & $1.03(0.88$ to 1.22$)$ & $0.94(0.74$ to 1.19$)$ & 1.04 (0.92 to 1.17$)$ \\
\hline \multicolumn{5}{|c|}{$\mathrm{UFP}_{\mathrm{NC}} \S$ (particles $/ \mathrm{m}^{3}$ ) } \\
\hline $\mathrm{n}$ & 144 & 157 & 151 & 179 \\
\hline $\operatorname{Lag} 0$ & $0.71(0.44$ to 1.16$)$ & $0.82(0.62$ to 1.09$)$ & $1.00(0.67$ to 1.49$)$ & $0.85(0.68$ to 1.05$)$ \\
\hline Lag 1 & $0.88(0.56$ to 1.38$)$ & $0.92(0.70$ to 1.21$)$ & $0.93(0.68$ to 1.26$)$ & $0.91(0.75$ to 1.10$)$ \\
\hline $\operatorname{Lag} 2$ & $1.60(0.92$ to 2.67$)$ & $0.88(0.67$ to 1.16$)$ & $1.03(0.73$ to 1.44$)$ & $1.00(0.81$ to 1.24$)$ \\
\hline Lag 3 & 1.07 (0.67 to 1.73$)$ & $0.79(0.59$ to 1.06$)$ & $0.89(0.63$ to 1.27$)$ & $0.84(0.70$ to 1.02$)$ \\
\hline Lag 4 & $1.50(0.89$ to 2.54$)$ & $0.99(0.76$ to 1.29$)$ & $0.62(0.44$ to 0.89$)$ & $0.88(0.73$ to 1.05$)$ \\
\hline 3-day mean & $1.92(0.98$ to 3.76$)$ & $0.83(0.58$ to 1.17$)$ & $0.72(0.49$ to 1.04$)$ & 0.85 (0.68 to 1.07$)$ \\
\hline \multicolumn{5}{|l|}{$\mathrm{NO}_{2}(\mathrm{ppb})$} \\
\hline $\mathrm{n}$ & 190 & 171 & 155 & 196 \\
\hline Lag 0 & $0.78(0.61$ to 1.00$)$ & $0.99(0.85$ to 1.17$)$ & $1.00(0.82$ to 1.22$)$ & $0.93(0.82$ to 1.05$)$ \\
\hline Lag 1 & $0.82(0.67$ to 1.01$)$ & $1.03(0.86$ to 1.24$)$ & $0.94(0.78$ to 1.13$)$ & $0.95(0.84$ to 1.06$)$ \\
\hline $\operatorname{Lag} 2$ & $1.12(0.88$ to 1.42$)$ & $1.07(0.90$ to 1.26$)$ & $1.12(0.94$ to 1.36$)$ & $1.09(0.97$ to 1.21$)$ \\
\hline Lag 3 & $1.42(1.15$ to 1.77$) \ddagger$ & $0.99(0.80$ to 1.22$)$ & $1.20(0.98$ to 1.46$)$ & $1.13(0.99$ to 1.30$)$ \\
\hline $\operatorname{Lag} 4$ & $1.33(1.06$ to 1.68$) \$$ & $1.06(0.89$ to 1.26$)$ & $1.00(0.82$ to 1.21$)$ & $1.09(0.96$ to 1.23$)$ \\
\hline 3-day mean & 1.45 (1.08 to 1.95$) \ddagger$ & $1.09(0.85$ to 1.40$)$ & $1.19(0.98$ to 1.45$)$ & $1.19(1.01$ to 1.30$)$ : \\
\hline \multicolumn{5}{|l|}{$\mathrm{NO}_{\mathrm{x}}(\mathrm{ppb})$} \\
\hline $\mathrm{n}$ & 190 & 171 & 155 & 196 \\
\hline Lag 0 & 0.84 (0.68 to 1.02$)$ & $0.98(0.85$ to 1.12$)$ & $1.00(0.84$ to 1.19$)$ & $0.94(0.85$ to 1.04$)$ \\
\hline Lag 1 & $0.82(0.69$ to 0.98$)$ & $1.02(0.87$ to 1.19$)$ & $0.90(0.77$ to 1.05$)$ & $0.92(0.84$ to 1.02$)$ \\
\hline Lag 2 & 1.05 (0.87 to 1.28$)$ & $1.06(0.92$ to 1.22$)$ & $1.11(0.95$ to 1.30$)$ & $1.07(0.97$ to 1.17$)$ \\
\hline $\operatorname{Lag} 3$ & 1.30 (1.09 to 1.53$) \$$ & $0.99(0.83$ to 1.18$)$ & $1.12(0.95$ to 1.33$)$ & $1.09(0.98$ to 1.22$)$ \\
\hline Lag 4 & $1.26(1.03$ to 1.54$) \$$ & $1.03(0.89$ to 1.19$)$ & $1.01(0.85$ to 1.19$)$ & $1.07(0.96$ to 1.19$)$ \\
\hline 3-day mean & $1.30(1.03$ to 1.65$) \ddagger$ & 1.09 (0.89 to 1.32$)$ & $1.14(0.97$ to 1.35$)$ & $1.14(1.00$ to 1.30$) \neq$ \\
\hline \multicolumn{5}{|l|}{ CO (ppm) } \\
\hline $\mathrm{n}$ & 190 & 172 & 154 & 196 \\
\hline Lag 0 & $0.82(0.61$ to 1.10$)$ & $1.04(0.80$ to 1.36$)$ & $1.04(0.75$ to 1.44$)$ & $0.96(0.80$ to 1.15$)$ \\
\hline Lag 1 & $0.77(0.57$ to 1.04$)$ & $1.05(0.79$ to 1.40$)$ & 0.94 (0.68 to 1.29$)$ & $0.92(0.77$ to 1.10$)$ \\
\hline Lag 2 & $1.05(0.77$ to 1.42$)$ & $1.10(0.86$ to 1.42$)$ & $1.16(0.90$ to 1.50$)$ & $1.08(0.92$ to 1.28$)$ \\
\hline $\operatorname{Lag} 3$ & $1.47(1.10$ to 1.96$) \div$ & $0.89(0.67$ to 1.18$)$ & $1.08(0.80$ to 1.46$)$ & $1.07(0.90$ to 1.26$)$ \\
\hline $\operatorname{Lag} 4$ & $1.19(0.86$ to 1.64$)$ & $0.94(0.72$ to 1.22$)$ & $1.04(0.76$ to 1.43$)$ & $1.02(0.84$ to 1.23$)$ \\
\hline 3-day mean & $1.33(0.94$ to 1.90$)$ & $0.97(0.70$ to 1.34$)$ & $1.13(0.81$ to 1.55$)$ & $1.07(0.87$ to 1.32$)$ \\
\hline
\end{tabular}

$\mathrm{Cl}$, confidence interval; $\mathrm{CO}$, carbon monoxide; COPSAC, Copenhagen Prospective Study on Asthma in Childhood; IQR, interquartile range; $0 \mathrm{R}$, odds ratios; $\mathrm{NO}_{\mathrm{x}}$, nitrogen oxide; $\mathrm{NO}_{2}$, nitrogen dioxide; $\mathrm{PM}_{10}$, particulate matter $<10 \mu \mathrm{m}$ in diameter; $\mathrm{UFP}_{\mathrm{NC}}$, ultrafine particles.

${ }^{*}$ Odds ratios estimated per IQR of a pollutant in a single-pollutant model adjusted for age, gender, smoking, paternal asthma history, temperature and season. $\uparrow$ Number of COPSAC children in the model.

$\mathrm{tp}<0.05$.

$\S$ Total concentration of ultrafine particles $10-700 \mathrm{~nm}$ in diameter (95\% of total concentration comes from particles $<100 \mathrm{~nm})$.

effects of $\mathrm{PM}_{10}$ and gases were observed, with consistently stronger estimates for gases $\left(\mathrm{NO}_{2}\right.$ and $\left.\mathrm{NO}_{\mathrm{x}}\right)$, proxies of trafficrelated pollution. Furthermore, adverse effects of $U_{F P}$ in infants, which were enhanced in infants living within a $5 \mathrm{~km}$ radius of the monitor, support the relevance of traffic, although an apparently protective effect of $\mathrm{UFP}_{\mathrm{NC}}$ was observed at the age of 3 years.

The finding that traffic triggers wheezing in infants is in agreement with recent evidence that infant wheezing is associated with proximity to $\operatorname{traffic}^{23}$ and infant wheezing bronchitis is associated with $\mathrm{PM}_{2.5} \cdot{ }^{26}$ Furthermore, two studies found an association between doctor-diagnosed asthma and respiratory symptoms (cough) in children aged $<2$ years and modelled levels of $\mathrm{PM}_{2.5}$ and $\mathrm{NO}_{2}$ at the children's residence. ${ }^{24} 25$ These associations were strongest in the first years of life, as observed in our study. Lung anatomy and physiology, ventilation rates and organ maturity change with age, which may explain the greater vulnerability of infants to air pollution and suggest biological plausibility for these findings. ${ }^{2}$ Consistent with our findings, a study of asthma symptoms in preschool children ${ }^{21}$ and several studies of asthma exacerbations in school children have also shown adverse effects of various proxies of traffic. ${ }^{16-19}$ 
Table 4 Associations between incident wheezing symptoms for 3-day mean concentrations (lag 2-4) of air pollutants in infants (age 0-1 years) in period with available $\mathrm{PM}_{10}$ measurements (12 December 1998 to 19 December 2004)

\begin{tabular}{|c|c|c|c|c|}
\hline & One-pollutant model & Two-pollutant model & Two-pollutant model & Two-pollutant model \\
\hline & $\mathrm{OR}^{*}(95 \% \mathrm{Cl})$ & OR (95\% Cl) & OR (95\% Cl) & OR (95\% Cl) \\
\hline $\mathrm{n}+$ & 189 & 189 & 189 & 189 \\
\hline $\mathrm{PM}_{10}\left(\mu \mathrm{g} / \mathrm{m}^{3}\right)$ & $1.21(0.99$ to 1.48$)$ & $1.13(0.88$ to 1.45$)$ & $1.16(0.90$ to 1.48$)$ & $1.23(0.96$ to 1.57$)$ \\
\hline $\mathrm{NO}_{2}(\mathrm{ppb})$ & $1.46(1.05$ to 2.02$) \$$ & $1.34(0.90$ to 1.99$)$ & & \\
\hline $\mathrm{NO}_{\mathrm{x}}(\mathrm{ppb})$ & $1.31(1.01$ to 1.68$) \$$ & & 1.21 (0.89 to 1.64$)$ & \\
\hline CO (ppm) & $1.27(0.86$ to 1.89$)$ & & & $1.03(0.64$ to 1.6$)$ \\
\hline
\end{tabular}

CO, carbon monoxide; $\mathrm{NO}_{\mathrm{x}}$, nitrogen oxide; $\mathrm{NO}_{2}$, nitrogen dioxide; $\mathrm{PM}_{10}$, particulate matter $<10 \mu \mathrm{m}$ in diameter.

* Odds ratios estimated per IQR of a pollutant and 3-day mean (lag 2-4 days) adjusted for age, gender, exposure to smoking, paternal asthma history, temperature and season. $\uparrow$ Number of COPSAC children in the model.

$\$ \mathrm{p}<0.05$.

Our study is the first to study the effects of UFPs on triggering of wheezing symptoms in young children. A positive association was found in the first year of life, which was significant in children living within $5 \mathrm{~km}$ of the monitor. The only other study of UFPs in children found a significant effect of $\mathrm{PM}_{10}$ and a comparable but not significant effect of UFPs on peak expiratory flow in 39 asthmatic school children over 57 days. ${ }^{8}$ Three studies of the effects of pollution on asthma exacerbations in adults found that UFPs and $\mathrm{PM}_{2.5}$ had a greater effect than larger particles ${ }^{33-35}$ in a radius of $2 \mathrm{~km}^{33}$ and $5 \mathrm{~km}^{34}$ from the pollution monitor. However, our results should be taken with caution and need to be confirmed because of the unexpected protective effect of UFPs found in children over 1 year of age.

To date, the effects of $\mathrm{PM}_{10}$ have been studied in only one survey of preschool children ${ }^{22}$ and there have been no studies in infants. In Copenhagen the main source of $\mathrm{PM}_{10}$ is longrange transport from secondary biomass and oil combustion sources with a smaller contribution from traffic, ${ }^{36}$ which suggests that $\mathrm{PM}_{10}$ is a poor proxy for traffic and enables its effects to be separated from and compared with the effects of traffic proxies $\left(\mathrm{NO}_{2}, \mathrm{NO}_{\mathrm{x}}\right.$, and $\left.\mathrm{UFP}_{\mathrm{NC}}\right)$. We found that the adverse effects of $\mathrm{PM}_{10}$ were significant only in infants (lag 3) and were generally smaller than those of gases (table 4) and $\mathrm{UFP}_{\mathrm{NC}}$ (table 5). This suggests an independent effect of particle mass and gases or particle numbers mainly related to traffic.

The increased susceptibility to air pollution in genetically susceptible children was previously suggested by the finding of an increase in the association of incident wheezing bronchitis with $\mathrm{PM}_{2.5}$ in children with a family history of asthma ${ }^{26}$ and the stronger effects of $\mathrm{O}_{3}$ in triggering wheeze in children of mothers with asthma. ${ }^{27}$ In our cohort of high-risk infants, associations with traffic-related air pollution were higher than those reported elsewhere in healthy infants, ${ }^{22} 2425$ but direct comparisons are difficult because of differences in outcome definitions and the use of geographical variation in exposure assessments in those studies. Furthermore, the association of asthma prevalence with traffic was surprisingly stronger for school children without a family history of asthma. ${ }^{17}$ This may indicate that early symptoms in infants and later diagnosed asthma-although strongly related-represent children with different susceptibilities.

The incidence of wheezing symptoms was chosen as the health outcome in this study rather than diagnoses of asthma because of the inaccurate diagnostic criteria for asthma in early life..$^{29}{ }^{30}$ As the term "wheeze" carries little specific meaning in lay terms and even between specialists ${ }^{37}$ we explained the term to the parents in the generic sense as lung symptoms severely affecting the child's well-being including wheeze or whistling sounds, breathlessness, shortness of breath and persistent troublesome cough. This approach was supported by diary reviews at the 6-monthly visits together with a dedicated book describing the relevant lung symptoms. The diagnosis and dayto-day management of respiratory conditions was conducted solely by the doctors employed for this purpose at the CRU in accordance with predefined algorithms, minimising the risk of symptom misclassification from influence of the prevailing and variable diagnostic criteria and treatment traditions in the medical community. The inaccuracy of symptom recognition and reporting bias was reduced by the fact that all mothers had a personal asthma history and familiarity with the disease. Furthermore, the state-of-the art information on the incidence of wheezing symptoms in the COPSAC cohort provided an opportunity to study the short-term effects of air pollution on triggering symptoms which has previously been reported in only

Table 5 Associations between incident wheezing symptoms for 3-day mean concentrations (lag 2-4) of air pollutants in infants (age 0-1 years) in period with available UFP $\mathrm{NC}_{\mathrm{NC}}$ measurements (15 May 2001 to 19 December 2004)

\begin{tabular}{|c|c|c|c|c|c|}
\hline & One-pollutant model & Two-pollutant model & Two-pollutant model & Two-pollutant model & Two-pollutant model \\
\hline & $0 R^{*}(95 \% \mathrm{Cl})$ & OR $(95 \% \mathrm{Cl})$ & OR $(95 \%$ Cl) & OR $(95 \% \mathrm{Cl})$ & OR $(95 \%$ Cl) \\
\hline$n \dot{n}$ & 144 & 144 & 144 & 144 & 144 \\
\hline $\mathrm{PM}_{10}\left(\mu \mathrm{g} / \mathrm{m}^{3}\right)$ & 2.05 (1.26 to 3.32$) \neq$ & $1.76(1.12$ to 2.76$) \$$ & & & \\
\hline $\mathrm{NO}_{2}(\mathrm{ppb})$ & $2.15(1.02$ to 4.57$) t$ & & $1.47(0.53$ to 4.06$)$ & & \\
\hline $\mathrm{NO}_{\mathrm{x}}(\mathrm{ppb})$ & $1.73(0.94$ to 3.22$)$ & & & $1.18(0.50$ to 2.78$)$ & \\
\hline
\end{tabular}


Table 6 Associations between incident wheezing symptoms for 3-day mean concentrations (lag 2-4) of air pollutants in 110 children living within a $5 \mathrm{~km}$ radius of the central monitor

\begin{tabular}{|c|c|c|c|c|}
\hline & Age 0-1 & Age 1-2 & Age 2-3 & Age 0-3 \\
\hline & $\mathrm{OR}^{*}(95 \% \mathrm{CI})$ & OR $(95 \% \mathrm{Cl})$ & OR $(95 \% \mathrm{CI})$ & OR (95\% Cl) \\
\hline$n+$ & 102 & 81 & 70 & 103 \\
\hline $\mathrm{n}$ & 76 & 78 & 70 & 95 \\
\hline $\mathrm{UFP}_{\mathrm{NC}} \S$ (particles $/ \mathrm{m}^{3}$ ) & $2.46(1.04$ to 5.84$) \neq$ & 1.09 (0.61 to 1.94$)$ & $0.40(0.21$ to 0.76$) \$$ & 0.92 (0.63 to 1.34 ) \\
\hline $\mathrm{n}$ & 103 & 81 & 70 & \\
\hline $\mathrm{NO}_{\mathrm{x}}(\mathrm{ppb})$ & $1.46(0.97$ to 2.21$)$ & 1.37 (0.98 to 1.91$)$ & $0.93(0.67$ to 1.28$)$ & $1.23(1.00$ to 1.51$)$ \\
\hline $\mathrm{n}$ & 103 & 83 & 70 & 104 \\
\hline CO (ppm) & $1.40(0.83$ to 2.36$)$ & 1.32 (0.75 to 2.34$)$ & $0.81(0.46$ to 1.40$)$ & $1.18(0.85$ to 1.63$)$ \\
\hline
\end{tabular}

$\mathrm{CO}$, carbon monoxide; $\mathrm{NO}_{\mathrm{x}}$, nitrogen oxide; $\mathrm{NO}_{2}$, nitrogen dioxide; $\mathrm{PM}_{10}$, particulate matter $<10 \mu \mathrm{m}$ in diameter; UFP $\mathrm{NC}_{\text {, }}$ ultrafine particles.

${ }^{*}$ Odds ratios estimated in a single-pollutant model per log IQR of a pollutant and 3-day mean (lag 2-4 days) adjusted for age, gender, exposure to smoking, paternal asthma history, temperature and season.

$\uparrow$ Number of COPSAC children in the model.

$\$ \mathrm{p}<0.05$.

$\S$ Total concentration of ultrafine particles $10-700 \mathrm{~nm}$ in diameter (95\% of total concentration comes from particles $<100 \mathrm{~nm}$ ).

two studies in infants. ${ }^{26}{ }^{27}$ Analyses of the cohort at later ages when the diagnoses of health outcomes are more specific will help determine the long-term impact of early exposure to air pollution on the development of specific respiratory diseases, including asthma.

The strengths of our study include the prospective daily recording of symptoms which allowed the study of symptom incidence, and the long study period of 5 years which gave sufficient contrast in exposure over time and power to detect adverse effects. This is an advantage over earlier studies with a short follow-up of a few months, ${ }^{4-10} 27$ which may limit the power to detect pollutant effects. ${ }^{38}$ An additional strength is the well-defined birth cohort of children genetically predisposed to asthma, giving a unique opportunity to study the effect of early exposure to air pollution in a high-risk group. Furthermore, continuously updating the residential information allowed inclusion criteria to be based on address (vicinity to the monitor) at the time of symptoms and not at the time of birth, as has previously been the case. ${ }^{21}{ }^{24}$ Finally, the availability of both gaseous and particulate pollutants of different sizes allowed comparisons of the effects of traffic-related (gases and UFPs) and non-traffic-related $\left(\mathrm{PM}_{10}\right)$ air pollution in the development of respiratory disease in young children.

The limitations of the study include assessment of exposure from a single monitor which might result in exposure misclassification. ${ }^{39}$ A $15 \mathrm{~km}$ radius from the central monitor was chosen as it represents the municipality limits of Copenhagen City with similar population and traffic density, and was assumed to be representative of air pollution levels measured at the central monitor. We have previously shown that the $\mathrm{UFP}_{\mathrm{NC}}$ levels at this site correlated well with levels at a monitoring site at the kerbside ( $2 \mathrm{~m}$ height) of a busy street $3000 \mathrm{~m}$ away (Spearman correlation coefficient $R_{S}=0.62$ ) and $a$ rural monitoring site located in a residential area $30 \mathrm{~km}$ southwest $\left(R_{S}=0.80\right) .{ }^{40}$ This was despite the fact that $U_{F C}$ levels were on average 4.6 times higher at the kerbside and 0.7 times lower at the rural site than at the urban background site. This indicates that the daily oscillations in traffic-related air pollutants on busy streets due to variation in traffic intensity, weather conditions and other factors are also reflected by urban background monitoring, and that a radius of $15 \mathrm{~km}$ from the background monitor is reasonable for the assessment of daily variations in population exposure. In children living closer to the central monitor $(5 \mathrm{~km})$ there was a slightly stronger association between $\mathrm{UFP}_{\mathrm{NC}}$ and triggering of wheeze which was statistically significant and exceeded that of other pollutants (table 6). However, if the apparent difference between estimates for a radius of $5 \mathrm{~km}$ and $15 \mathrm{~km}$ is real, we do not know whether this is due to a greater misclassification of exposure with the larger radius or whether the effects of traffic closer to the monitor-where traffic density and emissions and traffic pollutant levels are higher-really are greater. A further limitation of the study is the counterintuitive and biologically implausible change in the effect of UFP $_{\mathrm{NC}}$ from an adverse effect in infants to a protective effect in children over the age of 2 years which was statistically significant in children living within $5 \mathrm{~km}$ of the air pollution monitor (table 6). However, the effect of all other pollutants $\left(\mathrm{PM}_{10}, \mathrm{NO}_{2}, \mathrm{NO}_{\mathrm{x}}\right.$ and $\left.\mathrm{CO}\right)$ also attenuated after the age of 2 years to become apparently protective, although this did not reach statistical significance (table 6). This indicates that a decrease in susceptibility to air pollution after the age of 2 years is not confined to UFPs and is therefore probably not the result of measurement error or change in exposure but, rather, is due to the underlying disease process and/or the treatment of wheezing symptoms in this group of children. As the medication protocol in the COPSAC cohort presumes a history of recurring wheezing episodes, children typically do not receive medication until the second year of life or later. The attenuation of the adverse effects of air pollution after the age of 1 year and further after the age of 2 years is therefore most likely explained by the decreased susceptibility of the children to air pollution as a result of medication for their wheezing symptoms. Likewise, the statistical significance with respect to $U_{F P}$ is most likely explained by a type I error. Nevertheless, it may question the findings for $\mathrm{UFP}_{\mathrm{NC}}$ in the first year of life as no other supportive data are available. Further limitations of the study include the large number (54\%) of missing data for $U_{F P}$. However, missing data gaps were examined and were found to be random and not associated with pollution levels or weather conditions. Nevertheless, our UFP $_{\mathrm{NC}}$ measurements for 602 days are the longest available to date for the study of the effects of UFP on respiratory symptoms. ${ }^{8}{ }^{33-35}$

In summary, we found independent effects of $\mathrm{PM}_{10}$ and traffic-related pollution measured by exposure to $\mathrm{NO}_{2} / \mathrm{NO}_{\mathrm{x}}$, $\mathrm{CO}$ and $\mathrm{UFP}_{\mathrm{NC}}$ (5 $\mathrm{km}$ radius) in triggering wheezing symptoms 
in young children genetically predisposed to asthma. Infants were found to be particularly vulnerable. Follow-up of the cohort at later ages will determine the effect of these associations on the development of asthma.

Acknowledgements: We thank the children and parents who participated in this study.

Funding: The statistical analyses were supported by the Danish Research Council grant number 2052-03-16, AIRPOLIFE (Air Pollution in a Life Time Health Perspective) and the Danish Environmental Protection Agency. The COPSAC cohort study is funded by research funds from the Pharmacy Foundation of 1991; the Lundbeck Foundation; the Augustinus Foundation; Ronald McDonald House Charities; the Danish Medical Research Council; the Danish Pediatric Asthma Center; Direktør, cand. pharm. K Gad Andersen og Hustrus Familiefond; Aage Bangs Fond; Danish Lung Association; Kai Lange og Gunhild Kai Langes Fond; Direktør Ib Henriksens Fond; Gerda og Aage Hensch's Fond; Rosalie Petersens Fond; Hans og Nora Buchards Fond; Dagmar Marshalls Fond; Foundation of Queen Louise Children Hospital; the Danish Hospital Foundation for Medical Research, Region of Copenhagen, the Faroe Island and Greenland; Gangsted Fond; Højmosegård-Legatet; Fonden til Lægevidenskabens Fremme; A P Møller og Hustru Chastine Mc-Kinney Møllers Fond til almene Formaal; The Danish Ministry of the Interior and Health's Research Centre for Environmental Health. The study received support from the following pharmaceutical companies: AstraZenaca; LEOpharma; Pharmacia-Pfizer and Yamanouchi Pharma.

\section{Competing interests: None.}

Ethics approval: The COPSAC study was conducted in accordance with the Declaration of Helsinki and approved by the Copenhagen Ethics Committee and the Danish Data Protection Agency.

\section{REFERENCES}

1. Kocevar VS, Bisgaard $H$, Jönsson $L$, et al. Variations in pediatric asthma hospitalization rates and costs between and within Nordic countries. Chest 2004;125:1680-4.

2. Schwartz J. Air pollution and children's health. Pediatrics 2004;113:1037-43.

3. Thurston GD, Bates DV. Air pollution as an underappreciated cause of asthma symptoms. JAMA 2003:290:1915-7.

4. Delfino RJ, Zeiger RS, Seltzer JM, et al. Symptoms in pediatric asthmatics and air pollution: differences in effects by symptom severity, anti-inflammatory medication use and particulate averaging time. Environ Health Perspect 1998;106:751-61.

5. Delfino RJ, Zeiger RS, Seltzer JM, et al. Association of asthma symptoms with peak particulate air pollution and effects modification by anti-inflammatory medication use. Environ Health Perspect 2002;110:607-17.

6. Mortimer KM, Neas LM, Dockery DW, et al. The effect of air pollution on inner-city children with asthma. Eur Respir J 2002:19:699-705.

7. Ostro B, Lipsett M, Mann J, et al. Air pollution exacerbation of asthma in AfricanAmerican children in Los Angeles. Epidemiology 2001;12:200-8.

8. Pekkanen J, Timonen KL, Ruuskanen J, et al. Effects of ultrafine and fine particles in urban air on peak expiratory flow among children with asthmatic symptoms. Environ Res 1997:74:24-33.

9. Rabinovich N, Strand M, Gelfand EW. Particulate levels are associated with early asthma worsening in children with persistent disease. Am J Respir Crit Care Med 2006;173:1098-105.

10. Timonen KL, Pekkanen J. Air pollution and respiratory health among children with asthmatic or cough symptoms. Am J Respir Crit Care Med 1997;156:546-52.

11. Ward DJ, Ayres JG. Particulate air pollution and panel studies in children: a systematic review. Occup Environ Med 2004;61:e13.

12. Yu 0, Sheppard L, Lumley $\mathrm{T}$, et al. Effects of ambient air pollution on symptoms of asthma in seattle-area children enrolled in the CAMP study. Environ Health Perspect 2000;108:1209-14.

13. Roemer W, Hoek G, Brunekreef B, et al. Daily variation in air pollution and respiratory health in a multicentre study: the PEACE project. Eur Respir J 1998;12:1354-61.
14. Schildcrout JS, Sheppard L, Lumley T, et al. Ambient air pollution and asthma exacerbations in children: an eight-city analysis. Am J Epidemiol 2006;164:505-17.

15. Schlesinger RB, Kunzli N, Hidy GM, et al. The health relevance of ambient particulate matter characteristics: coherence of toxicological and epidemiological inferences. Inhal Toxicol 2006;18:95-125.

16. Gauderman WJ, Avol E, Lurmann F, et al. Childhood asthma and exposure to traffic and nitrogen dioxide. Epidemiology 2005;16:737-43.

17. McConnell R, Berhane K, Yao L, et al. Traffic, susceptibility, and childhood asthma Environ Health Perspect 2006;114:766-72.

18. Nicolai T, Carr D, Weiland SK, et al. Urban traffic and pollutant exposure related to respiratory outcomes and atopy in a large sample of children. Eur Respir J 2003;21:956-63.

19. Venn AJ, Lewis SA, Cooper M, et al. Living near a main road and the risk of wheezing illness in children. Am J Respir Crit Care Med 2001;164:2177-80.

20. Zmirou D, Gavin S, Pin I, et al. Traffic related air pollution and incidence of childhood asthma: results of Vesta case-control study. J Epidemiol Community Health 2004;58:18-23.

21. Brauer M, Hoek G, Smit HA, et al. Air pollution and development of asthma, allergy and infections in a birth cohort. Eur Respir J 2007;29:1-10.

22. Pierse N, Rushton L, Harris RS, et al. Locally generated particulate pollution and respiratory symptoms in young children. Thorax 2006;61:216-20.

23. Ryan PH, LeMasters MS, Biagini J, et al. Is it traffic type, volume, or distance? Wheezing in infants living near truck and bus traffic. J Allergy Clin Immunol 2005;116:279-84.

24. Brauer $\mathbf{M}$, Hoek $G$, van Vliet $P$, et al. Air pollution from traffic and the development of respiratory infections and asthmatic and allergic symptoms in children. Am J Respir Crit Care Med 2002;166:1092-8.

25. Gehring U, Cyrys J, Sedlmeir G, et al. Traffic-related air pollution and respiratory health during the first 2 yrs of life. Eur Respir J 2002;19:690-8.

26. Pino $\mathbf{P}$, Walter $\mathrm{T}$, Oyarzum $\mathrm{M}$, et al. Fine particulate matter and wheezing illnesses in the first year of life. Epidemiology 2004;15:702-8.

27. Triche EW, Gent JF, Holford TR, et al. Low-level ozone exposure and respiratory symptoms in infants. Environ Health Perspect 2006;114:911-6.

28. Bisgaard H. The Copenhagen Prospective Study on Asthma in Childhood (COPSAC): design, rationale, and baseline data from a longitudinal birth cohort study. Ann Allergy Asthma Immunol 2004;93:381-9.

29. Bisgaard $\mathbf{H}$, Hermansen MN, Loland L, et al. Intermittent inhaled corticosteroids in infants with episodic wheezing. N Engl J Med 2006;354:1998-2005.

30. Bisgaard $\mathbf{H}$, Hermansen MN, Buchvald F, et al. Childhood asthma after bacterial colonization of the airway neonates. N Engl J Med 2007:357:1487-95.

31. Ketzel M, Wahlin P, Berkowicz R, et al. Particle and trace gas emission factors under urban driving conditions in Copenhagen based on street and roof-level observations. Atmos Environ 2003:37:2735-49.

32. Liang K-Y, Zeger SL. Longitudinal data analyses using generalized linear models. Biometrika 1986:73:13-22

33. Peters A, Wichmann HE, Tuch T, et al. Respiratory effects are associated with the number of ultrafine particles. Am J Respir Crit Care Med 1997;155:1376-83.

34. Penttinen $\mathbf{P}$, Timonen $\mathrm{KL}$, Tiittanen $\mathbf{P}$, et al. Ultrafine particles in urban air and respiratory health among adult asthmatics. Eur Respir J 2001;17:428-35.

35. Von Klot S, Wolke G, Tuch $T$, et al. Increased asthma medication use in association with ambient fine and ultrafine particles. Eur Respir J 2002;20:691-702.

36. Andersen ZJ, Wahlin P, Raaschou-Nielsen 0, et al. PM ambient particle source apportionment and daily hospital admissions among children and elderly in Copenhagen. J Expo Sci Environ Epidemiol 2007;17:625-36.

37. Cane RS, McKenzie. Parents' interpretations of children's respiratory symptoms on video. Arch Dis Child 2001;84:31-4.

38. Roemer W, Hoek G, Brunekfreef B. Pollution effects on asthmatic children in Europe, the PEACE study. Clin Exp Allergy 2000;30:1067-75.

39. Pekkanen J, Kulmala M. Exposure assessment of ultrafine particles in epidemiologic time-series studies. Scand J Work Environ Health. 2004;30(Suppl 2):9-18.

40. Andersen ZJ, Wahlin P, Raaschou-Nielsen 0 , et al. Size distribution and total number concentration of ultrafine and accumulation mode particles and hospital admissions in children and the elderly in Copenhagen, Denmark. Occup Environ Med 2007 Nov 7 [Epub ahead of print]. 